\title{
Progress Report on the Midwest Inter-Library Center
}

\author{
Mr. Esterquest is director, Midwest \\ Inter-Library Center, Chicago.
}

T SHOULD like to begin my remarks with a brief review of the purpose and objectives of the Midwest Inter-Library Center (M.I.L.C.). I do so because there continue to be misconceptions concerning the real aims of this new cooperative enterprise. There are still librarians who think of the Midwest Inter-Library Center as merely another storage library. This may be detected one way or another. If the librarian does not come out and say that the center is going to be a huge warehouse for storing all the dead books in the Midwest, he says the same thing when he refers to the center as "the librarian's Fort Knox."

The M.I.L.C. intends to take the regional storage idea and carry it a few steps further. The first step is to tackle the problem of eliminating duplicates. If the Universities of Illinois, Iowa, Minnesota and Chicago each have a set of the stenographic proceedings of the German Reichstag, and each chooses to send its set to the M.I.L.C. for regional housing, we are committed to a policy of looking quite critically at the four assembled sets and asking ourselves how many are actually needed to serve the research program of the Midwest. If the answer is that only one set is needed, then the policy of the center is to dispose of the other three.

1 Paper presented at the meeting of the University Libraries Section, A.C.R.L., 'Cleveland, July 20, 1950.
This is the first step: the elimination of duplication of existing holdings. The next step is to eliminate duplicate efforts to maintain current files. When it takes over a set the M.I.L.C. undertakes also the responsibility of maintaining the set for the region as a whole. Thus one subscription suffices where four existed before ; one checking card, one claiming activity, one binding activity.

There is a third and a fourth step. Suppose that in addition to receiving on deposit the proceedings of the German Reichstag, the center also receives the proceedings of parliaments of some 25 other countries. It seems logical to us that in such an event these two further steps be taken: one, the collection should be examined for gaps within sets, and the M.I.L.C. should attempt to fill in those gaps; and two, the center should, after analyzing the research needs of the region, round out the collection by acquiring similar files of parliamentary proceedings from nations not represented in the nucleus group of 25 . Thus the regional cooperative library intends to play a positive role in providing for its supporting libraries well-rounded and useful collections within the defined area of little-used research materials.

What are little-used research materials? These are generally publications which are taking space and not paying their way in reader use. They are housed, rearranged, rebound, and sometimes recataloged against the day when someone may need them. 
They are records of possible important use to some phase of scholarship or investigation. They may be obsolescent, they may discourage readers because they are in minor languages or they may appeal to only small groups of specialists in a world increasingly given to areas of very specialized knowledge.

By assuming responsibility for the housing of such books the M.I.L.C. gives member libraries freedom in the use of space in their individual libraries for books which have a larger and more constant research audience. It saves the library the cost of the erection of new buildings, it gives the library a guarantee of absorbing the present-day useful books when they become little-used and it enables a member library to concentrate its efforts in the direction of servicing the more frequently-used materials.

Among the many classes of less-used books and library materials about which midwestern librarians have been giving thought are the following io classes which have been designated as part of the initial program of the M.I.L.C.: State documents, including legislative journals; older text books; foreign and American dissertations; college catalogs; trade journals; house organs ; foreign parliamentary proceedings; telephone directories; and newspapers.

After the initial period there will be other classes: Files of old or obscure periodicals; proceedings and reports of certain learned societies; trade unions; charitable organizations; old editions of encyclopedias; year books; minor fiction; poetry and drama; official gazettes; and early census reports and many other types of materials that do not fall into large class categories.

To give its member libraries space relief is the first part of the M.I.L.C. program. But it is not all of the program. From the point of view of the research faculty, the second part is more important than the first.
It concerns the original acquisition of materials not now in the libraries of any of the member institutions. When the center procures a set of foreign parliamentary proceedings not now owned by any of the participating libraries, it adds an item to the over-all research resources of the region. As this rounding out of its collections proceeds, there will emerge important values in terms of regional enrichment in research materials. The presses of the world are turning out many more publications than even the wealthiest individual library can hope to acquire.

In summary it may be said that the M.I.L.C. should make it possible for a participating librarian to administer his library on a more economical and practical basis. Instead of his library becoming crow ted with materials of limited use, thus leading it to become a library with a high proportion of inactive records, the responsibility for maintaining these inactive records is transferred to the central agency. The individual library is thus free to stock its shelves with books that have enough use to justify their everyday presence. If it does not have to add as often or as much to a building or space program, it is able to hold down the size of the staff to actual reader needs and to eliminate the expense involved in staff that is present merely because the administration of dead material requires more hands.

I should like now to report on the major events and accomplishments of the M.I.L.C.

Ten midwestern universities organized, on Mar. 4, I949, the Midwest InterLibrary Corporation, on whose board of directors each of the Io participating universities was represented. The original io were the University of Chicago, Illinois Institute of Technology, the University of Illinois, Indiana University, State University of Iowa, the University of Kansas, 
Michigan State College, the University of Minnesota, Northwestern University and Purdue University. During the next few months three rlew universities elected participation: Wisconsin, Cincinnati and Notre Dame. At present two more institutions are in process of applying for membership; and, of course, we have an open-door policy in regard to new members. ${ }^{2}$ The representatives of the universities have cooperated in formulating policies and planning the development of the corporation's functioning agency, the Midwest Inter-Library Center.

Early in I949 a capital gift of one million dollars became available to the corporation through two substantial gifts: The Carnegie Corporation of New Yor:- provided $\$ 750,000$, and the Rockefeller Foundation made a gift of $\$ 250,000$. The capital fund is being used to erect and equip the building in Chicago which will house the M.I.L.C., and it is paying for organizational expenses.

Last July the Board of Directors provided for regular annual income by devising a formula for pro-rating the center's annual operating budget among participating institutions. This formula, based on each institution's book fund, Ph.D. program and nearness to Chicago, represents an experimental attempt to measure in advance the service demands to be expected from each participating university. On the basis of the adopted formula, the 13 participating universities supported a \$I2,000 Inter-Library Center budget during the fiscal year ended June 1950. The budget for the current year has been increased to $\$ 33,000$, an amount being shared again among the membership. On Oct. I, I949, a full-time director assumed his duties and established an office of the M.I.L.C. in Chicago.

In addition to planning a building, the Board of Directors, the participating li-

\footnotetext{
2 John Crerar Library became a member in October,
}

brarians and the director have worked together to spell out the policies needed to implement the general objectives agreed upon at the time of incorporation. Some knotty problems have arisen. For example, if duplication in holdings is to be eliminated, then the libraries sending material for housing in the center must relinquish title to the books they send. Since most of the participating institutions are state universities whose charters do not permit the general liquidation of state property, the problem of reconciling a desired process with legal limitations seemed formidable. The solution adopted may not be final, but we feel that it is the best possible under the circumstances. It provides for four different categories of deposit and for the participating library to elect the one that is appropriate for each case:

Category A-Outright gift, title of ownership relinquished.

Category B-Title of ownership retained by depositing library but deposit is permanent so long as the center shall last.

Category C-Title of ownership retained by the depositing library; deposit understood to be indefinite but subject to recall at the will of the depositing library.

Category D-Rental storage for temporary space relief.

Groundwork has been laid for internal operation and the activities that will begin when the building is opened next April. Study was made to determine how best to maintain immediate direct communication between the M.I.L.C. and its participating libraries. It has been decided that a teletype network will be created using the Bell Teletypewriter Exchange System. This will enable libraries to get in touch immediately with the center, so that material needed on a local campus can be dispatched shortly after it is requested. The research scholar may thus feel assured that material housed in Chicago will be available for his use on his home campus the day after he asks for it. 
/Decisions have been reached providing for the reproduction of catalog cards in the center so that each participating library will have a catalog record of the holdings of the central agency in Chicago. Detailed plans for the transportation of the initial deposits have been made. The center will own and operate its own truck.

A regional photoreproduction program is accepted as one of the center's activities, and a committee 'of the participating libraries will soon begin work on the details of a plan for microfilming newspapers.

A major portion of attention during recent months, however, has been given to planning the building which is to house the M.I.L.C. During the spring of 1949 the Board of Directors accepted one of four offers of land on which the building might be erected. The site chosen, a gift of the University of Chicago, is in the 5700 block on Cottage Grove Avenue on Chicago's south side. Since October an architect has been at work planning a building designed in terms of its special functions. Particular attention has been given to a comparison of different methods of book storage, and in March it was voted to equip the major portion of the building stacks with a new type of hinged compact storage shelving developed for the center by Snead \& Company. Both the hinged storage stacks and the plan $\checkmark$ to shelve most of the books by size rather than by subject class will greatly increase the potential capacity of the stacks building that has been designed. Table I illustrates the degree of space-gain achieved by these two methods.

\section{TABLE I}

Space and Cost Savings of Size-Shelving and Hinged Stacks

A. Total book capacity of M.I.L.C. stacks space (5I 4,500 cu. ft.) using:

I. Conventional stacks and conventional class shelving 755,000 vols.

2. Conventional stacks and size- shelving

2,090,000 vols.

3. Hinged stacks and size-shelving $3,150,000$ vols.

B. Cost of total building construction per volume of stack capacity:

I. Typical large libraries $\$ 2.40$

2. New England Deposit Library (I94I)

3. M.I.L.C. with conventional stacks

4. M.I.L.C. with hinged storage stacks

The plans adopted are for a building consisting of two major portions: ( 1 ) seventier bookstacks covering an area $90^{\prime} \times 98^{\prime}$ with each tier $8^{\prime}$ high in the clear, the column-spacing at intervals of $6^{\prime} \times 7^{\prime} 4^{\prime \prime}$ and the anticipated capacity of the stacks portion is in the neighborhood of $3,000,000$ volumes of books and 20,000 volumes of newspapers. (2) A work-study area $30^{\prime} \times 185^{\prime}$, most of which will be one-story high but which will have a second story at one end providing individual study cubicles for visiting scholars. The exterior design will show large facades of windowless stacks in a light gray brick, with the work-study building reaching across the front constructed in brick of contrasting color. Ground was broken on July II, and it is expected that the completed building will be ready for occupancy in April 1951.

Thus we move forward into the second half of the twentieth century. The twin problems of the ever-expanding research library and the ever-increasing multiplicity of research materials are still with us. No one pretends that the M.I.L.C. is a perfect solution to these big problems of our age. However, I should like to venture to say that there is hope for the future as long as librarians and their administrators are willing to face the problems realistically and to experiment. The M.I.L.C. is an experiment. The group of librarians who are behind it have high hopes that they have created an efficient device. 